\title{
It Rings a Bell or Breeds Contempt? Activating Background Knowledge and Reading Recall
}

\author{
Mohammad Ali Heidari-Shahreza \\ Department of English, Faculty of Humanities, Shahreza Branch, Islamic Azad University, \\ Shahreza, Iran \\ E-mail address: maheidari.sh@gmail.com
}

\begin{abstract}
Keywords: Background knowledge, Reading recall, Cultural familiarity, Schema theory, Persian literature.
\end{abstract}

\begin{abstract}
The present study examined the possible effects of activating background knowledge on reading recall of 20 Iranian EFL learners by giving the experimental participants a text from Persian literature, a culturally-familiar source, and contrasting their key points recall with those of another group of learners who did not know the text origin. Findings revealed that the participants who did not know the source of the text did significantly better than the experimental group who were given the source and the context. While a small-scale study, this study may suggest that using culture-based reading materials may not always help the learners' reading performance. In addition, the activation of background knowledge may result in overreliance on prior knowledge resources and trigger affective barriers such as lack of interest which may be to the detriment of readers' recall.
\end{abstract}

\section{INTRODUCTION}

Textual characteristics play an important role in readers' ability to understand and recall the content of a text [1]. Moreover, reading is a cyclical process through which a reader relies on his/her background knowledge to revise and reconstruct the semantic features of the text $\mathrm{s} / \mathrm{he}$ reads [2]. Therefore, the relevant literature suggests that activating background knowledge may help learners' reading uptake by connecting their schemata (i.e. mental stores of information) to the semantic features of text. In other words, reading is an interactive task in which readers decode the individual bits of textual content through a bottom-up process while they also verify their predictions based on their background knowledge through a top-down parallel process [3].

This interactive view of reading process has urged a notable number of textbook writers to choose reading materials from learners' own culture on the ground that such culturally-familiar texts activate the learners' prior knowledge faster and more in accordance with the semantic features of reading passages than excerpts from a second or foreign culture [4]. A question raised by some scholars, however, is that what if the learners rely on their background knowledge excessively (see for example [5]. It is likely that such overreliance on top-down processing of reading discourage learners to pay attention to the semantic details or mislead them to reconstruct the content of the text more based on their prior knowledge than what the text actually signifies.

This study intended to address this challenging question by verifying whether or not Iranian EFL learners would benefit from reading an English text translated from Persian literature with which they were culturally familiar.

\section{METHODS}

Based on [5], through a quasi-experimental design, this study explored the possible effects of reading culturally-familiar texts on Iranian EFL learners' reading recall. It sought to answer the following research question:

1. What are the possible effects of reading texts from Persian literature (the participants' own culture) on their reading recall?

2.1. Participants. This study's target population was the learners participating in a lowintermediate EFL program at a language center in Iran during the winter term of 2014. Out of those 
learners who signed consent forms 20 were randomly selected. The sample, then, was randomly divided into two equal groups: Group A and group B. The former was given the source and the context of the text while the latter was deprived of the text background. Results are reported from the 20 students who completed all tasks. Age, education, socio-cultural background and other extraneous factors were kept under control.

2.2. Instruments and materials. The elicitation instrument for this study was an English version of a famous Persian story generally known as 'Pooria Valy' (see Appendix A). This story has widely been retold for centuries among Iranian people and is defensibly a part and parcel of Persian literature. It is the story of an Iranian wrestler of high virtue who decides to lose a fight versus an Indian rival to mend the broken heart of his rival's mother who has been anxious about her son's important fight.

2.3. Data collection. Participants in Group A received some information on the source of the passage including the story's title, which could trigger the participants' background knowledge on the content of the story. Group B, however, were given a text without an indicative title. They were then instructed to read their respective texts only once but careful enough to comprehend the texts. There was no time limit at this stage of the research. Having finished the texts, the participants got involved in their regular class activities for about half an hour to block the possible effects of shortterm memory on their reading recall. Afterwards, following [5], the learners were instructed to note in English (and in rare cases, Persian) what they could recall from the texts they had read. The participants' notes were, then, employed to indentify their levels of reading recall.

2.4. Data analysis. The participants' notes were scored by the researcher using different levels of recall based on the four-point system designed for the study. Each note was rated from 1 to 4 points depending on their salience and relevance to the original text. Four points were devoted to the units having the greatest semantic significance and one point to the least (see Table 1).

Table1. Scoring scale of key points recall

\begin{tabular}{cl}
\hline Point & \multicolumn{1}{c}{ Interpretation } \\
\hline 4 & information essential to the story, and telegraphic account of the story \\
3 & important but not necessarily essential information \\
2 & additional or redundant information that helped to reveal the story's completeness \\
1 & trivial or subordinate information, which least affects the story line \\
\hline
\end{tabular}

\section{RESULTS}

Table 2 shows the results obtained from Group A (whose participants were given the source specifications e.g. the story's title) and Group B (who didn't know the story origin). The former recalled a mean of $43.2 \%$ of the text's key points compared to $61.3 \%$ for Group B. A $t$-test analysis revealed a significant difference between the means of the two groups ( $t(18)=-3.98 ; p<05)$. Therefore, the results indicated that the participants who did not recognize the source of the text recalled the content significantly better than those who knew the source (see also Fig. 1).

Table2. Key points recall: Group A \& B comparison

\begin{tabular}{lcc}
\hline Specifications & Group A* & Group B** \\
\hline Sample size & 10 & 10 \\
Mean (\% idea units) & 43.2 & 61.3 \\
Standard deviation & 6.9 & 9.7 \\
Minimum (\%) & 40.6 & 46.8 \\
Maximum (\%) & 57.2 & 81.9 \\
\hline
\end{tabular}

Note:* : Source given (SG), **: Not source given (NSG). 


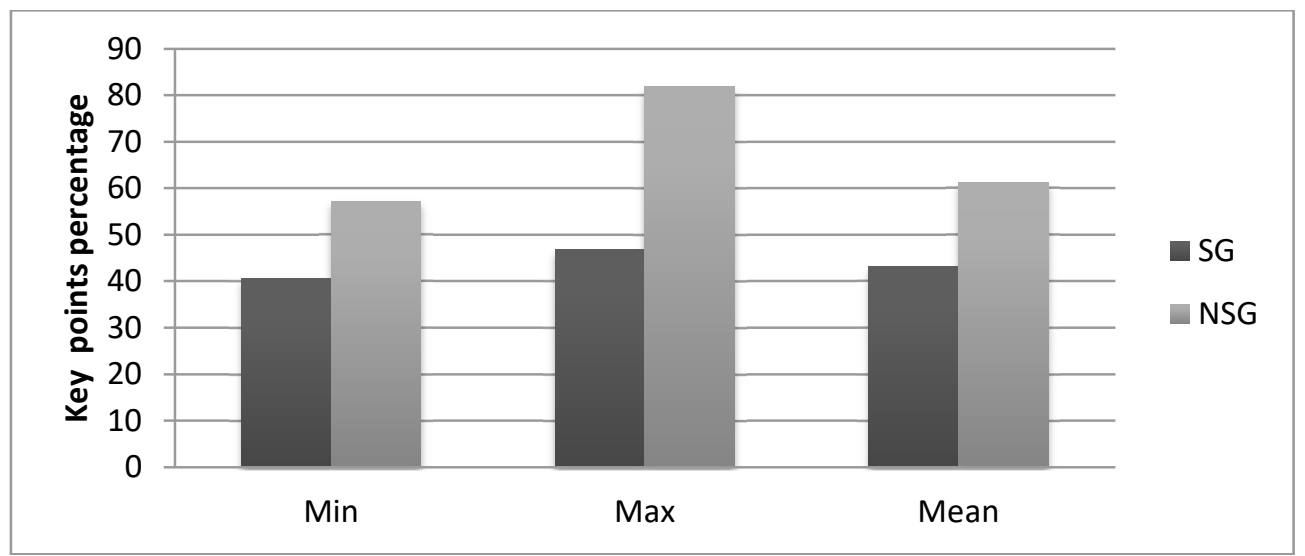

Fig.1. Group A \& B comparison on key points recall

\section{DISCUSSION}

The results seem to challenge the literature on the positive effects of background knowledge and learners' familiarity. That's to say, the EFL learners in group B who did not receive information on the origin of their reading outperformed their counterparts in group A who knew the text was a translation of a famous Persian story. These findings which are in line with [5], question the effectiveness of activating background knowledge as a facilitator of reading recall. While further research is needed, schema theory might explain these contrasting findings based on the notion of "overreliance on knowledge-based or top-down processing" [6], also concluded in [5]. As [7] points out "if learners can rely extensively on top-down processing they may pay little attention to the form of the input and may therefore not acquire anything new" (p. 279). Therefore, it might be the case that the participants in group A, paid less attention to the important details than those in group $\mathrm{B}$ who embarked on reading task with no prior knowledge.

Moreover, readers in group A whose background knowledge was activated by giving the title and the source of the original text may have felt confused by the discrepancies between the idea units of their reading and the version they had already in mind particularly regarding time and place details. Finally, the EFL learners in group A, might have been less motivated for they were instructed to read and understand a text with which they already felt familiar. The readers in group $\mathrm{B}$, however, began their reading task, supposing the text content was (entirely) new.

\section{CONCLUSION}

This small-scale study investigated the possible effects of using texts from EFL learners' own culture on their reading recall. Contrary to the existing literature but in line with [5], the findings revealed that the overreliance on background knowledge may be to the detriment of the learners' reading performance and recall.

This, in turn, may suggest that EFL teachers and materials writers should also consider the side effects of using culturally-familiar texts. While such texts have definitely some advantages over unfamiliar ones, the learners might not perform or feel as expected on these texts [8]. [9] reports that some textbook writers may not choose to include culturally-familiar texts for EFL learners because "they feel learners would not be interested in reading them."

The present study had some limitations. First, it was a small-scale study employing a limited number of EFL learners in one language center. Secondly, different age groups other than adults and a larger sample encompassing other proficiency levels could widen this study's generalizability. Further studies may extend the scope of this study by adding qualitative measures of reading recall. Finally, it is recommended that interested researchers explore the possible effects of background knowledge on the learners' retention in the long run. 


\section{Appendix A}

\section{The Great Athlete}

It was really an important day. All people had come to see the wrestling on the first of June. It meant a lot to everyone. The great athlete of the city, a strong man in late thirties, was going to fight with a young Indian wrestler. Before long, the fight began. The first five minutes passed. The Indian wrestler was not as strong as the great athlete. He was out of breath. Almost everyone was sure that the young Indian wrestler was going to lose the fight. But who knows what will happen next in a fight? Surprisingly, a few minutes to the end of first quarter, the great athlete shocked all people when he finally made his big decision. People couldn't believe their eyes. The great athlete, the wrestler who had been always a winner, lost the fight to win the smile of a worried mother who wished his young son defeat the great athlete of the city. No one could understand how it happened and why.

Some people say, after that day, the great athlete traveled to a far city where no one knew him and became the great athlete of that city. But others say he stayed in his city. Anyway, after that day, he was not only a great athlete but also a great man. People loved him not because of his many gold medals .Young or old, man or woman; all people loved their great athlete because he had a heart of gold.

\section{References}

[1] Callender A. A., Medina, A., Brantmeier, C., Textual enhancements or interference? Inserted adjuncts and L2 reading with intermediate language learners. System, 41(4), 952-964 (2013).

[2] Alptekin C., Cultural familiarity in inferential and literal comprehension in L2 reading. System, 34 (4), 494-508, (2006).

[3] Schotter E. R., Lee M., Reiderman M., Rayner K., The effect of contextual constraint on parafoveal processing in reading. Journal of Memory and Language, 83, 118-139, (2015).

[4] Miller D., ESL reading textbooks vs. university textbooks: Are we giving our students the input they may need? Journal of English for Academic Purposes, 10 (1), 32-46, (2011).

[5] Stott N., Familiarity breeds contempt: Reading texts from learners' own cultures does not guarantee recall. TESOL Quarterly, 38 (2), 345-352, (2004).

[6] Carrell P. L. Some causes of text-boundedness and schema interference in ESL reading. In P. L. Carrell, J. Devine, \& D. E. Eskey (Eds.), Interactive Approaches to Second Language Reading. Cambridge: Cambridge University Press, 1988, pp. 101-113.

[7] R. Ellis, The Study of Second Language Acquisition. Oxford: Oxford University Press, 1994.

[8] Heidari-Shahreza M. A., The effect of content-based language instruction on EFL learners' attention, engagement, volunteering and verbal Interaction. International Letters of Social and Humanistic Sciences, 20, 14-21, (2014).

[9] Byram, M., Feng, A., Intercultural authenticity: A new angle for content analysis. Paper presented at the conference Culture, Language, and Communication, University of Hong Kong. Retrieved July 2, 2002, from http:// www.hku.hk/language/clc/intercultural_authenticity.html, (2000, September). 